\title{
Twenty-four-hour energy expenditure in Pima Indians with Type 2 (non-insulin-dependent) diabetes mellitus
}

\author{
A. M. Fontvieille, S. Lillioja, R.T. Ferraro, L. O. Schulz, R. Rising and E. Ravussin \\ Clinical Diabetes and Nutrition Section, National Institute of Diabetes and Digestive and Kidney Diseases, National Institutes of Health, \\ Phoenix, Arizona, USA
}

\begin{abstract}
Summary. To assess the impact of Type 2 (non-insulin-dependent) diabetes mellitus on energy metabolism, 24-h energy expenditure, basal metabolic rate and sleeping metabolic rate were measured in a respiratory chamber in 151 Pima Indians, 102 with normal glucose tolerance (67 male/35 female, (mean $\pm \mathrm{SD}$ ) $28 \pm 7$ years, $99 \pm 24 \mathrm{~kg}, 32 \pm 9 \%$ body fat) and in 49 with Type 2 diabetes ( 22 male 27 female, $35 \pm 11$ years, $107 \pm 33 \mathrm{~kg}, 39 \pm 7 \%$ body fat), after at least 3 days on a weight maintaining diet. After adjustment for differences in fat-free mass, fat mass, age and sex, 24-h energy expenditure, basal metabolic rate and sleeping metabolic rate were significantly higher in diabetic patients than in control subjects $(72 \mathrm{kcal} /$ day, $p<0.05 ; 99 \mathrm{kcal} / \mathrm{day}, p<0.005$; $99 \mathrm{kcal} /$ day, $p<0.001$ respectively). Spontaneous physical activity was similar in both groups whereas the thermic effect of food, calculated as the mean energy expenditure corrected
\end{abstract}

for activity throughout the day above sleeping metabolic rate and expressed as a percentage of energy intake, was significantly lower in Type 2 diabetic patients $(17.1 \pm 7.1$ vs $19.8 \pm 5.6 \%, p<0.05)$. Adjusted values of 24 -h energy expenditure, basal metabolic rate and sleeping metabolic rate were correlated with hepatic endogenous glucose production $(r=0.22, p<0.05 ; r=0.22, p<0.05 ; r=0.31, p<0.01$ respectively). Therefore, increased basal and sleeping metabolic rates, resulting in increased 24 -h sedentary energy expenditure may play a role in the weight loss so often observed in Type 2 diabetic subjects in addition to the energy loss from glycosuria.

Key words: Energy expenditure, Type 2 (non-insulin-dependent) diabetes mellitus, indirect calorimetry, obesity, body composition, hepatic glucose production.
Obese subjects with Type 2 (non-insulin-dependent) diabetes mellitus lose weight after the diagnosis of diabetes [1-3]. Weight loss may be due to weight reducing therapy or to caloric loss as glucose in the urine or both. Caloric restriction seems an unlikely mechanism for longterm weight reduction as most obese non-diabetic subjects are unable to maintain reduced body weight with diet therapy [4]. Urinary glucose loss might therefore be a more important cause of negative energy balance and weight loss in these patients. Another contributing cause of weight loss might be an increase in resting energy expenditure as observed in lean Type 1 (insulin-dependent) diabetic patients [5] and in obese Type 2 diabetic subjects [6].

Resting metabolic rate, which is strongly correlated with body size and composition, accounts for approximately $75 \%$ of daily energy expenditure in sedentary adults [7]. Other components of daily expenditure such as thermogenesis and physical activity have a variable but significant impact on daily energy expenditure. Recent studies suggest a decreased thermogenic response to ingestion or infusion of glucose in obese diabetic patients $[8$, 9]. Also the level of spontaneous physical activity which accounts for a significant part of daily energy expenditure [10] can be altered in Type 2 diabetic patients. Studies have shown an increase in resting metabolic rate and a decrease in the thermic effect of food in subjects with Type 2 diabetes but no measurement of overall 24-h energy expenditure has been made in these patients. The potential for changes in daily energy expenditure which may contribute to weight loss was measured in subjects with Type 2 diabetes in this study.

We have tested the following hypotheses: (1) obese subjects with Type 2 diabetes have increased resting and sleeping metabolic rates resulting in increased daily energy expenditure compared to obese subjects with normal glucose tolerance. This increase can account in part for weight loss. (2) The putative increased energy expenditure is associated with the severity of hyperglycaemia and the level of hepatic glucose production. 


\section{Subjects, materials and methods}

\section{Subjects}

Between September 1985 and December 1990, Pima Indians were admitted to the metabolic research ward of the Clinical Diabetes and Nutrition Section of the National Institutes of Health in Phoenix, as part of an ongoing, longitudinal study of risk factors for the development of Type 2 diabetes and obesity. Volunteers have been restudied approximately once per year. On admission, subjects were in good health (apart from having diabetes or obesity or both) as assessed by a medical history, physical examination and blood screening. Subjects were fed a weight maintaining diet consisting of $50 \%$ carbohydrate, $20 \%$ protein, $30 \%$ fat. None of the subjects was taking any medication. From this group, we selected a subgroup of 151 subjects who had either normal glucose tolerance or Type 2 diabetes according to an oral glucose tolerance test given after at least 2 days on the weight maintaining diet and according to the World Health Organization criteria [11]. One hundred and two subjects ( 67 males, 35 females) had normal glucose tolerance and 49 (22 males and $27 \mathrm{fe}$ males) had Type 2 diabetes. The physical characteristics of the 151. subjects are listed in Table 1. Body composition was determined by underwater weighing with simultaneous determination of lung residual volume [12]. Body fat mass and fat-free mass (FFM) were calculated according to Keys and Brozek [13].

The studies were approved by the ethical committees of the National Institutes of Health and the Indian Health Service, and by the Gila River Indian Community. Informed consent was obtained from all the subjects.

\section{Energy expenditure measurements}

Twenty-four-hour energy expenditure (24EE) was measured in a respiratory chamber, which has been previously described [10]. Briefly, it consists of a sealed room through which fresh atmospheric air is continuously added. Fractions of the inflowing and outflowing air are sampled, dried by condensers in a $1{ }^{\circ} \mathrm{C}$ refrigerator, filtered for dust, and analysed for $\mathrm{CO}_{2}$ and $\mathrm{O}_{2}$ concentrations. Spontaneous physical activity is continuousiy monitored in the chamber by two microwave radar detectors and expressed as the percentage of time during which motion is detected.

After an overnight fast, each volunteer spent one day in the respiratory chamber. Measurements were performed continuously for $23 \mathrm{~h}$ from 08.00 to 07.00 hours the following day and then extrapolated to $24 \mathrm{~h}$. Sleeping metabolic rate (SMR) was defined as the average energy expenditure of all 15 -min periods between 23.00 and 05.00 hours during which spontaneous physical activity did not exceed $1.5 \%$ of the $15 \mathrm{~min}$. At 07.00 hours, the chamber was opened and, with the subject still lying in bed, a plastic, ventilated hood was placed over the head. After adaptation to the hood for approximately $15 \mathrm{~min}$, basal metabolic rate (BMR) was measured by connecting the hood system to the analyser equipment for 9-15 min.

The thermic effect of food was calculated as the integrated energy expenditure (after correcting for the effect of spontaneous physical activity by regression analysis) above the sleeping metabolic rate and expressed as the percentage of the energy intake as previously described [14]. This value includes both the thermic effect of food and the energy cost of arousal.

\section{Reproducibility of energy expenditure measurements}

To measure the reproducibility of the $24 \mathrm{EE}, \mathrm{BMR}$, SMR, therniceffect of food and spontaneous physical activity measurements, 20 of the 151 subjects were studied a second time in the respiratory chamber at least 1 week but less than 1 year apart. The subjects were selected for maintenance of body weight (body weight change $<2 \%$ )
Table 1. Physical characteristics of subjects (means $\pm S D$ )

\begin{tabular}{lccl}
\hline & $\begin{array}{l}\text { Non-diabetic } \\
\text { subjects } \\
n=102\end{array}$ & $\begin{array}{l}\text { Diabetic } \\
\text { subjects } \\
n=49\end{array}$ & $\begin{array}{l}p \text { value } \\
\text { (difference } \\
\text { in means) }\end{array}$ \\
\hline $\begin{array}{l}\text { Sex ratio (male/female) } \\
\text { Age (years) }\end{array}$ & $67 / 35$ & $22 / 27$ & \\
Weight (kg) & $28 \pm 7$ & $35 \pm 11$ & $<0.0001$ \\
Waist/thigh ratio & $1.68 \pm 0.20$ & $1.79 \pm 0.29$ & $<0.03$ \\
Body fat $(\%)$ & $32 \pm 9$ & $39 \pm 7$ & $<0.0001$ \\
$\begin{array}{l}\text { Fat-free mass (kg) } \\
\text { Fat mass (kg) }\end{array}$ & $66 \pm 13$ & $64 \pm 16$ & $=0.32$ \\
$\begin{array}{l}\text { Fasting plasma glucose } \\
\text { (mmol//) }\end{array}$ & $5.1 \pm 0.3$ & $8.9 \pm 3.2$ & $<0.0001$ \\
$\begin{array}{l}\text { 2-h post-load plasma } \\
\text { glucose (mmol/1) }\end{array}$ & $6.3 \pm 1.0$ & $16.2 \pm 4.0$ & $<0.0001$ \\
$\begin{array}{l}\text { Fasting plasma insulin } \\
(\mu U / m l)\end{array}$ & $37 \pm 19$ & $67 \pm 33$ & $<0.0002$ \\
$\begin{array}{l}\text { 2-h plasma insulin } \\
(\mu U / m l)\end{array}$ & $155 \pm 112$ & $296 \pm 244$ & $<0.01$ \\
\hline
\end{tabular}

and were fed a similar number of calories on both occasions $(2450 \pm 410 \mathrm{vs} 2525 \pm 457 \mathrm{kcal} /$ day $)$.

\section{Hepatic glucose production}

After at least 7 days on the metabolic ward, a two-step hyperinsulinaemic, euglycaemic clamp was performed [15] on a subset of 86 subjects ( 66 normal subjects, 20 diabetic subjects) as previously described [16]. During the baseline period of this procedure, tracer amounts of $\left[3{ }^{3} \mathrm{H}\right]$ glucose were infused for $2 \mathrm{~h}$ to measure the postabsorptive rate of hepatic glucose production [17].

\section{Statistical analysis}

The data are presented as means \pm SD except where otherwise indicated. Mean group effects were tested by non-paired $t$-test. Single and multiple regression analyses as well as analysis of co-variance were performed using the general linear model of the SAS Institute (Cary, NC, USA).

The intraclass correlation coefficient and the coefficient of variation were used to measure the reproducibility of the energy expenditure measurements in the 20 subjects who were measured twice.

In the diabetic subjects, the predicted metabolic rates were calculated on the basis of the regression equation generated in the 102 non-diabetic subjects using the individual's FFM, fat mass and sex for 24EE and SMR, and adding age (significant determinant) for BMR.

\section{Results}

The physical characteristics of the subjects are presented in Table 1 . The sex ratio was approximately $2: 1$ in favour of males in the group with normal glucose tolerance whereas females exceeded males in the diabetic group. The diabetic subjects were older and fatter than the nondiabetic subjects, but otherwise were similar for body weight and height. 


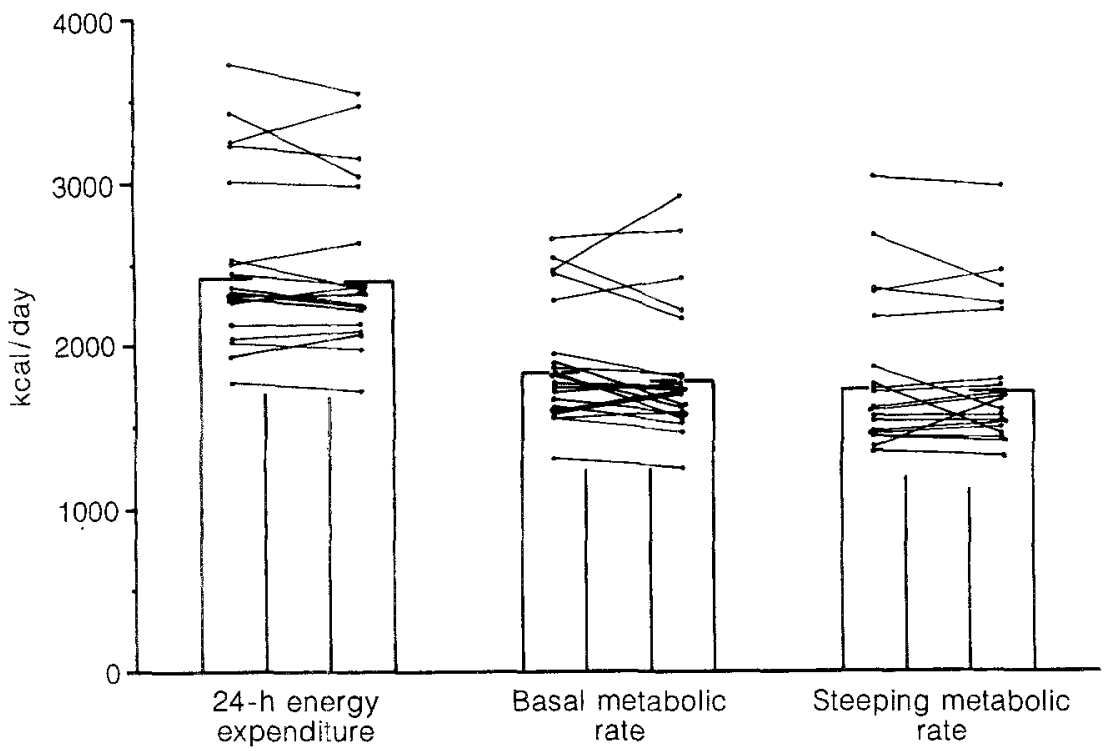

Fig. 1. Reproducibility of 24-h energy expenditure, basal metabolic rate and sleeping metabolic rate measured in 20 subjects. The mean coefficients of variation are $2.8 \%$ for 24 -h energy expenditure, $5.9 \%$ for basal metabolic rate and $4.7 \%$ for sleeping metabolic rate. The intraclass coefficient correlations are 0.98 for 24 -h energy expenditure, 0.89 for basal metabolic rate and 0.95 for sleeping metabolic rate
Energy expenditure, glucose tolerance and glucose clamp measurements

Repeated measurements were obtained in 20 subjects (12 male/ 8 female, 18 non-diabetic and 2 diabetic subjects, $29 \pm 6$ years; at first examination: $104 \pm 27 \mathrm{~kg}$, $32 \pm 9 \%$ fat; at second examination: $105 \pm 28 \mathrm{~kg}$, $32 \pm 8 \%$ fat). The mean coefficients of variation (CV) were $2.8 \%$ (range $0.1-8.9$ ) for $24 \mathrm{EE}, 5.9 \%(0.7-12.1$ ) for BMR, $4.7 \%(0.1-12.1)$ for SMR, $18.6 \%(1.0-50.6)$ for thermic effect of food and $19.9 \%(2.0-53.1)$ for spontaneous physical activity measurements (Fig. 1). The intraclass correlation coefficient $\left(\mathrm{r}_{\mathrm{i}}\right)$ from one measurement to another, was $0.98,0.89,0.95,0.43$ and 0.35 for $24 \mathrm{EE}, \mathrm{BMR}$, SMR, thermic effect of food and spontaneous physical activity respectively.

There was no significant difference between Type 2 diabetes compared to non-diabetic subjects with respect to absolute values of $24 \mathrm{EE}(2454 \pm 550$ vs $2404 \pm$ $391 \mathrm{kcal} /$ day respectively), BMR $(1891 \pm 430$ vs $1832 \pm$ $306 \mathrm{kcal} /$ day $)$ and SMR $(1812 \pm 435$ vs $1700 \pm$ $316 \mathrm{kcal} /$ day). The thermic effect of food was similar in both groups when expressed in absolute value $(413 \pm 242$ vs $458 \pm 130 \mathrm{kcal} /$ day) but lower in diabetic subjects when expressed as a percentage of energy intake $(17.1 \pm 7.1 \mathrm{vs}$ $19.8 \pm 5.6 \%, p<0.05)$. The level of spontaneous physical activity was similar in the two groups $(8.9 \pm 3.2$ vs $9.3 \pm 2.6 \%$ ).

By multiple linear regression analysis, the major determinant of energy expenditure was found to be FFM, explaining $82 \%$ of the variance in $24 \mathrm{EE}(p<0.0001), 74 \%$ of the variance in BMR $(p<0.0001)$ and $72 \%$ of the variance in SMR $(p<0.0001)$ (Table 2$)$. A statistically significant additional effect of fat mass $(p<0.001)$, sex $(p<0.0001)$ and diabetes status $(p<0.05)$ explained another $5 \%$ of the variance of $24 \mathrm{EE}\left(r^{2}=0.87\right)$ and $7 \%$ of the variance in BMR $\left(r^{2}=0.81\right)$. Only fat mass $(p<0.0001)$ and diabetes status $(p<0.005)$ had a significant additional effect as determinants of SMR explaining another $8 \%$ of the variance $\left(r^{2}=0.80\right)$.

Figure 2 shows the relationship between 24EE, BMR, SMR and FFM. For most of the diabetic subjects, the measured energy expenditure was higher than that predicted from the non-diabetic population, i. e. was above the re-

Table 2. Multiple regression analyses between 24 -h energy expenditure, basal metabolic rate, sleeping metabolic rate and fat-free body mass (FFM), fat mass (FM), age, sex and diabetes status

\begin{tabular}{|c|c|c|c|c|c|c|}
\hline $\begin{array}{l}\text { Intercept } \\
\text { (kcal/day) }\end{array}$ & $\begin{array}{l}\text { FFM } \\
(\mathrm{kg})\end{array}$ & $\begin{array}{l}\mathrm{FM} \\
(\mathrm{kg})\end{array}$ & $\begin{array}{l}\text { Age } \\
\text { (years) }\end{array}$ & $\mathrm{Sex}^{\mathrm{a}}$ & Diabetes status $^{\mathrm{b}}$ & $r^{2}$ \\
\hline \multicolumn{7}{|c|}{ 24-h energy expenditure } \\
\hline $\begin{array}{l}668 \pm 82 \\
(p<0.0001)\end{array}$ & $\begin{array}{l}20.3 \pm 2.0 \\
(p<0.0001)\end{array}$ & $\begin{array}{l}7.7 \pm 1.4 \\
(p<0.0001)\end{array}$ & & $\begin{array}{l}+213 \pm 46 \\
(p<0.05)\end{array}$ & $\begin{array}{l}72 \pm 31 \\
(p<0.0001)\end{array}$ & 0.87 \\
\hline \multicolumn{7}{|c|}{ Basal metabolic rate } \\
\hline $\begin{array}{l}710 \pm 93 \\
(p<0.0001)\end{array}$ & $\begin{array}{l}12.6 \pm 2.0 \\
(p<0.0001)\end{array}$ & $\begin{array}{l}7.3 \pm 1.4 \\
(p<0.0001)\end{array}$ & $\begin{array}{l}-4.0 \pm 1.6 \\
(p<0.05)\end{array}$ & $\begin{array}{l}+232 \pm 45 \\
(p<0.0001)\end{array}$ & $\begin{array}{l}+99 \pm 31 \\
(p<0.005)\end{array}$ & 0.81 \\
\hline $\begin{array}{l}365 \pm 80 \\
(p<0.0001)\end{array}$ & $\begin{array}{l}15.9 \pm 2.0 \\
(p<0.0001)\end{array}$ & $\begin{array}{l}6.9 \pm 1.4 \\
(p<0.0001)\end{array}$ & & $\begin{array}{l}+88 \pm 45 \\
(p=0.053)\end{array}$ & $\begin{array}{l}99 \pm 30 \\
(p<0.005)\end{array}$ & 0.80 \\
\hline
\end{tabular}



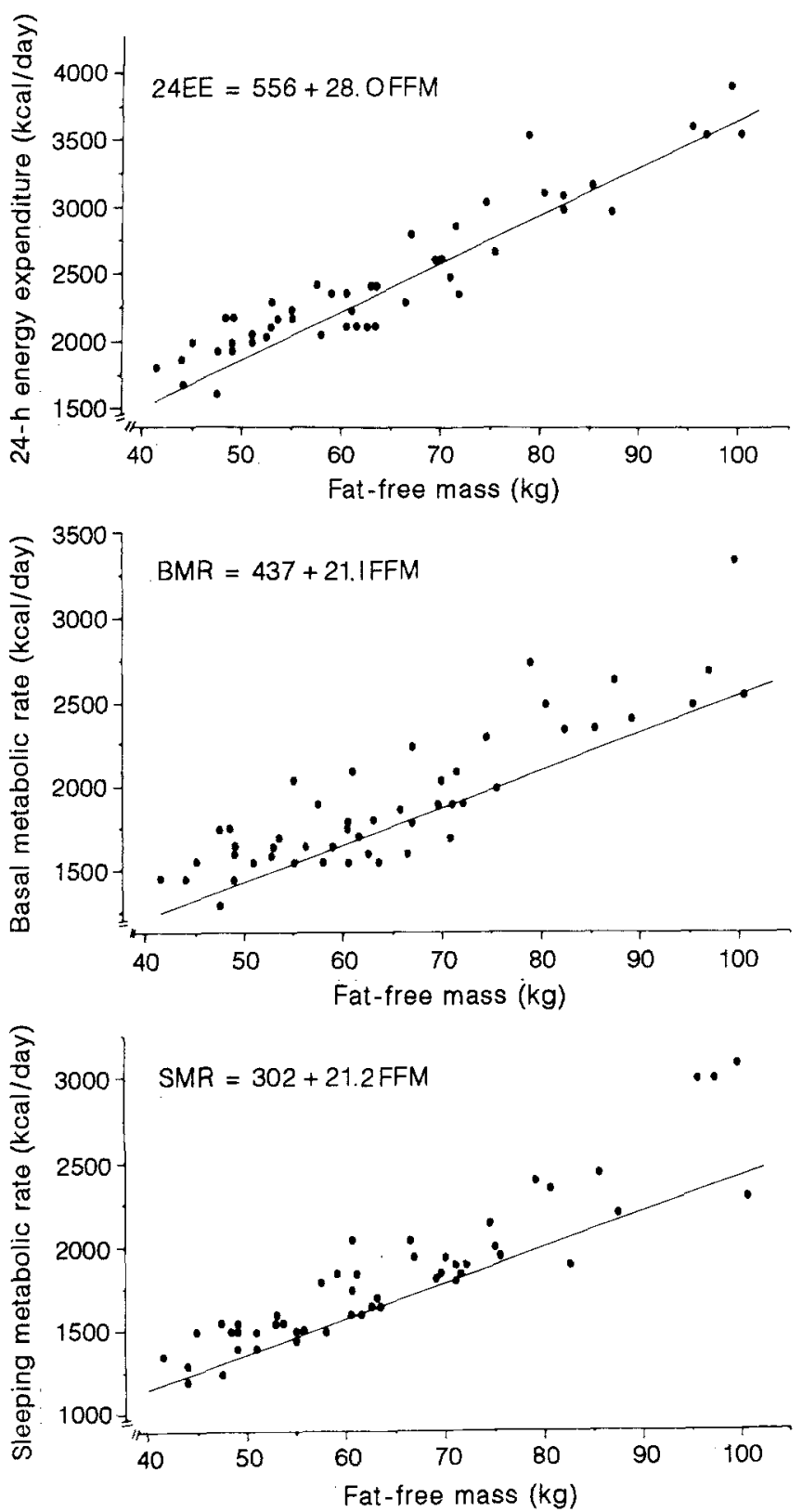

Fig. 2. Relationship between 24-h energy expenditure (upper panel), basal metabolic rate (middle panel) and sleeping metabolic rate (lower panel) and fat-free body mass in 102 non-diabetic subjects (-) and 49 diabetic subjects $(\bullet)$. Individual data are provided for diabetic subjects and the regression line is for the subjects with normal glucose tolerance

gression line for the normal glucose tolerant subjects. This is more clearly shown in Figure 3 where mean values of the differences between measured and predicted energy expenditure are presented. The mean value for $24 \mathrm{EE}$, BMR and SMR was significantly higher in diabetic than in control subjects ( $72 \pm 178 \mathrm{kcal} /$ day, $p<0.05 ; 99 \pm$ $185 \mathrm{kcal} /$ day, $p<0.005 ; 99 \pm 171 \mathrm{kcal} /$ day, $p<0.001$ ) corresponding to $2.9 \%, 5.2 \%$ and $5.4 \%$ of $24 \mathrm{EE}, \mathrm{BMR}$ and SMR, respectively.

Energy expenditure data were also compared with fasting plasma glucose, 2 -h post-load plasma glucose and post-absorptive hepatic glucose production. Adjusted values of $24 \mathrm{EE}(r=0.21, p<0.01), \operatorname{BMR}(r=0.23$,
A.M. Fontvieille et al.: Energy expenditure in Type 2 diabetic patients

$p<0.01)$ and SMR $r=0.16, p<0.05$ ) were positively correlated to fasting plasma glucose. Similar relationships were found between 2 -h post-load plasma glucose and adjusted values of 24EE $(r=0.20 ; p<0.01)$, BMR $(r=0.22$, $p<0.01)$ and SMR $(r=0.21, p<0.01)$. Plasma glucose area above fasting values during the oral glucose tolerance test were also correlated with adjusted values of $24 \mathrm{EE}(r=0.22 ; p<0.05)$, BMR $(r=0.22 ; p<0.01)$ and SMR $(r=0.26, p<0.01)$, suggesting that increased energy expenditure is associated with the degree of glucose intolerance. Hepatic endogenous glucose production was correlated with adjusted values of 24EE $(r=0.22 ; p<0.05)$, $\operatorname{BMR}(r=0.22 ; p<0.05)$ and $\operatorname{SMR}(r=0.31 ; p<0.01)$.

\section{Discussion}

Previous studies have reported an increased resting metabolic rate but decreased thermic effect of food $[6,8,9]$ in subjects with Type 2 diabetes. However, the resulting impacts of these two alterations on overall daily energy expenditure could only be speculated upon. This study demonstrates for the first time, in a larger number of subjects, that patients with Type 2 diabetes have higher 24EE, BMR and SMR than non-diabetic subjects, independently of differences in FFM, fat mass, age and sex. As often reported and also observed in this study, subjects with Type 2 diabetes are usually fatter than non-diabetic individuals. Therefore, we used multiple regression analysis to adjust for these differences between groups. The data confirm the results reported by Nair et al. [5] in lean Type 1 (insulin-dependent) diabetic subjects and by Bogardus et al. [6] who reported a $5 \%$ increase in resting energy expenditure of obese patients with Type 2 diabetes compared to control subjects. The $2.9 \%$ higher sedentary $24 \mathrm{EE}$, might explain some of the weight loss occurring after the onset of Type 2 diabetes [1] in addition to the effect of urinary energy losses. The thermic effect of food expressed as the percentage of energy intake was significantly lower in diabetic compared with control subjects. This observation confirms the findings of Golay et al. [18] who have shown a decreased thermogenic response to glucose ingestion in obese subjects with insulin resistance whereas the response was unaltered in young obese subjects without insulin resistance. In the present study, the significant lower thermic effect of food and the tendency for a lower level of spontaneous physical activity might explain why $24 \mathrm{EE}$ was only increased by $2.9 \%$ vs $5.4 \%$ for SMR.

The $72 \mathrm{kcal} /$ day increase in $24 \mathrm{EE}$ observed in diabetic subjects could account for a maximum $2.8 \mathrm{~kg}$ fat loss per year or $3.4 \mathrm{~kg}$ of adipose tissue loss. After the onset of diabetes, Knowler et al. [1] found a $3 \mathrm{~kg}$ weight loss in $62 \mathrm{Pi}$ ma Indians over 2 years. Changes in energy expenditure may therefore explain a part, if not all, of the weight loss occurring with Type 2 diabetes. Unfortunately, the 24EE measurement in a respiratory chamber does not include the energy cost of voluntary physical activity. It has been shown that diabetes was more frequent in physically inactive subjects than in their active counterparts in Fiji [19]. However, this relationship is not consistent across various 


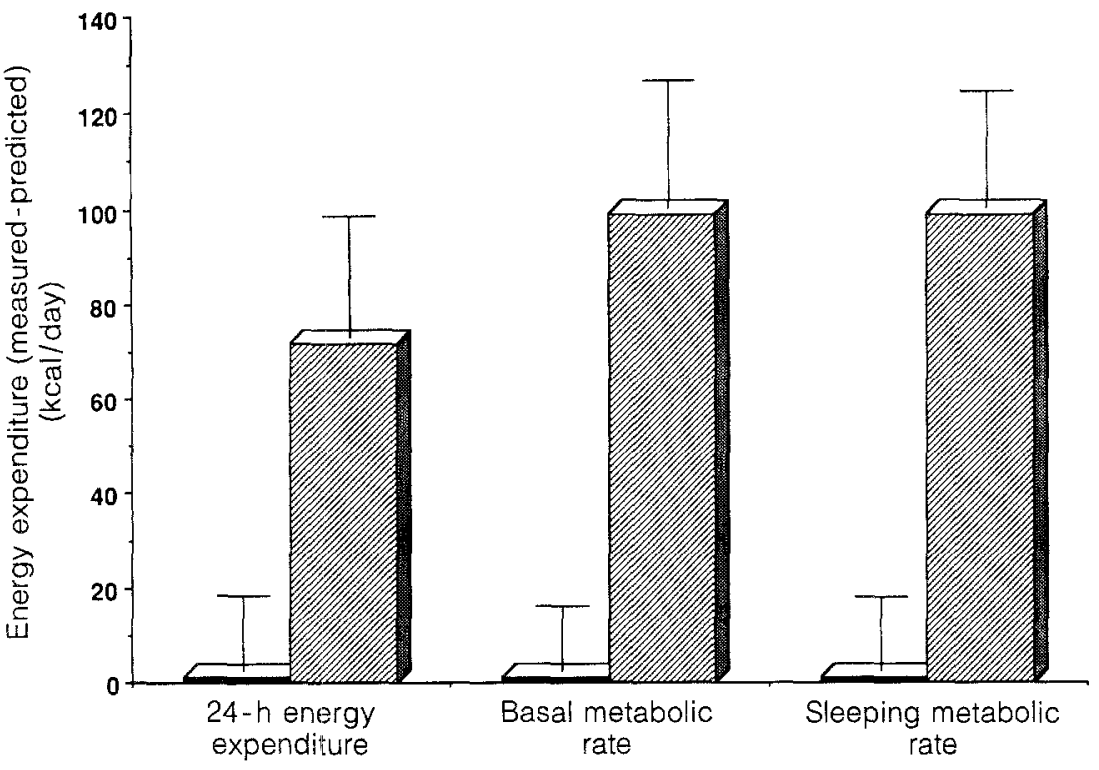

Fig.3. Deviation from predicted values of energy expenditure given as mean \pm SEM in 49 diabetic (羂) compared to 102 non-diabetic ) subjects. The predicted values were calculated from the equation derived in the 102 nondiabetic subjects with fat-free mass, age and sex as determinants of energy expenditure. Therefore, mean values are 0 for the non-diabetic subjects. Values were significant in diabetic subjects at $p<0.01$ race and gender subgroups based upon a wider evaluation of the Pacific data [20]. Therefore, studies using the double labelled water method [21] to assess daily free-living energy expenditure including physical activity are needed before and after the diagnosis of Type 2 diabetes to fully understand the role of physical activity in the pathogenesis of Type 2 diabetes and the importance of the change in energy expenditure in the weight loss following the onset of the disease.

Increased rates of energy expenditure in Type 2 diabetes could result from one of several mechanisms: increased protein turnover [5], increased rate of glucose cycling [22], increased gluconeogenesis [23], increased plasma glucagon [24] or increased sympathetic nervous activity [25]. Nair et al. [5] reported increased rates of protein synthesis and catabolism in subjects with poorly-controlled Type 1 diabetes. Protein synthesis is undoubtedly an energy-consuming process which may also be increased in Type 2 diabetes subjects [26], however, no data are available for this.

The reasons for the increased hepatic glucose production observed in Type 2 diabetes remain unclear [27-31]. Increased hepatic output might be due to increased glycogenolysis, increased gluconeogenesis or both. Felig et al. [23] found no significant difference in splanchnic uptake of the major gluconeogenic substrates (i.e. lactate, alanine and pyruvate) in Type 2 diabetes compared to nondiabetic subjects. Also, studies using conventional isotopic approaches in Type 2 diabetes subjects, have not consistently shown increased Cori cycle [32-34] or glucose-alanine cycle activity [35-37]. The inadequacy of methods used to quantify gluconeogenesis has been a major obstacle in determining the mechanism of the increased glucose output. Recently, Consoli et al. [38, 39] applied a new isotopic approach [40] to assess the relative contributions of gluconeogenesis and glycogenolysis to the increased hepatic glucose production reported in Type 2 diabetes subjects. They found that most of the increase in hepatic glucose output was related to an enhancement of gluconeogenesis.
Several mechanisms might contribute to the increased hepatic glucose output in Type 2 diabetic patients. In vitro studies indicate that non-esterified fatty acids can activate key-gluconeogenic enzymes such as pyruvic carboxylase and fructose 1,6-diphosphatase [41]. Therefore, the high circulating non-esterified fatty acid plasma concentration usually found in Type 2 diabetes may lead to an enhanced gluconeogenesis [31, 42]. In addition, increased levels of gluconeogenic precursors (lactate and glycerol) have been documented in Type 2 diabetic subjects [23]. Finally, hyperglucagonaemia is characteristic of Type 2 diabetes [43] and has been shown to play an important role in sustaining increased rites of hepatic glucose output [44]. Studies in dogs indicate that stimulation of glycogenolysis and gluconeogenesis are equally sensitive to glucagon [45]. In the context of insulin resistance with increased circulating non-esterified fatty acids and increased availability of gluconeogenic substrates, there is a possibility that hyperglucagonaemia preferentially promotes gluconeogenesis.

Other hormones playing a role in the regulation of gluconeogenesis, such as catecholamines and cortisol, may also contribute to the increment in energy expenditure. However, the discrepant observations showing that Type 2 diabetic subjects may have either lower or higher plasma concentrations of catecholamines compared to control subjects [46-48] do not clearly demonstrate an increased activity of the sympathetic nervous system in subjects with Type 2 diabetes.

Consoli et al. [38] also calculated [6] that increased gluconeogenesis could account for more than half of the rise in metabolic rate found in Type 2 diabetes patients. Since it is known that gluconeogenesis is enhanced during the night, the significant increase in SMR in Type 2 diabetes subjects corroborates these findings. Thus, gluconeogenesis might play a role in the increase in energy expenditure. Increased fasting hyperglycaemia in the diabetic subjects occurs as a result of both decreased insulin action and decreased peripheral insulin concentrations. Bogardus et al. [31] hypothesize that one of the major results of these 
changes in insulin action and secretion is increased flux of gluconeogenic substrates to the liver, leading to increased hepatic glucose production and progressive hyperglycaemia.

In summary, 24EE, BMR and SMR in Type 2 diabetic subjects are higher than that of non-diabetic subjects. In addition to caloric loss from glycosuria, increased BMR and SMR resulting in increased 24EE, may play an important role in weight loss in Type 2 diabetic subjects. The increased rate of gluconeogenesis might be one of the mechanisms responsible for the increase in metabolic rate.

Acknowledgments. We thank Ms. C. Massengill and the nursing staff of the Phoenix Clinical Research Section for their professional care of the volunteers and their assistance in performing the tests. Gratitude is expressed to Dr. M. Saad for his critical review of the manuscript and to Dr. A. Charles for her help with the statistics. We also thank Mr. T.Anderson, Ms. V. Boyce, Ms. I. Harper, Ms. H. Seagle for their technical help. Most importantly, we thank the volunteers.

\section{References}

1. Knowler WC, Pettitt DJ, Savage PJ, Bennett PH (1981) Diabetes incidence in Pima Indians: contributions of obesity and parental diabetes. Am J Epidemiol 113:144-156

2. Ravussin E (1990) Dépenses énergetiques chez l'obèse. In: Flammarion Médecine Sciences (eds) Journées de Diabétologie de l'Hôtel-Dieu, Paris, pp 41-50

3. Keen H, Jarett RJ, Mc Cartney P (1982) The ten-year follow-up of the Bedford survey (1962-1972) glucose tolerance and diabetes. Diabetologia 22: 73-78

4. Bray GA (1976) Treatment of the obese patient: use diet and exercise. In: Smith LH Jr (ed) The obese patient. W.B. Saunders, Philadelphia, pp 300-352

5. Nair KS, Halliday D, Garrow JS (1984) Increased energy expenditure in poorly controlled Type 1 (insulin-dependent) diabetic patients. Diabetologia 27:13-16

6. Bogardus C, Taskinen MR, Zawadzki J, Lillioja S, Mott D, Howard BV (1986) Increased resting metabolic rates in obese subjects with non-insulin-dependent diabetes mellitus and the effect of sulfonylurea therapy. Diabetes 35: 1-5

7. Ravussin E, Burnand B, Schutz Y, Jéquier E (1982) Twenty-four hour energy expenditure and resting metabolic rate in obese, moderately obese, and control subjects. Am J Clin Nutr 35: $566-$ 573

8. Golay A, Schutz Y, Felber JP, DeFronzo RA, Jéquier E (1986) Lack of thermogenic response to glucose/insulin infusion in diabetic obese subjects. Int J Obes 10: 107-116

9. Ravussin E, Zawadski K (1987) Thermic effect of glucose in non insulin-dependent diabetes mellitus. Diabetes 36: 1441-1447

10. Ravussin E, Lillioja S, Anderson TE, Christin L, Bogardus C (1986) Determinants of 24-hour energy expenditure in man: methods and results using a respiratory chamber. $J$ Clin Invest 78 : $1568-1578$

11. WHO Study Group (1985) Diabetes mellitus. World Health Organization technical reports, Series 727 . World Health Organization, Geneva, p 11

12. Goldman RF, Buskirk ER (1961) A method of underwater weighing and the determination of body density. In: Brozek J, Herschel A, (eds) Techniques for measuring body composition. National Academy of Sciences, Washington, DC, pp 78-89

13. Keys A, Brozek J (1953) Body fat in adult man. Physiol Rev 33: $245-325$

14. Schulz LO, Nyomba BL, Alger S, Anderson TE, Ravussin E (1991) Effect of endurance training on sedentary energy expenditure in a respiratory chamber. Am J Physiol 260: E257-E261
15. DeFronzo RA, Tobin ID, Andres R (1979) Glucose clamp technique: a method for quantifying insulin secretion and resistance. Am J Physiol 237: E214-E223

16. Lillioja S, Mott D, Zawadski JK et al. (1987) In vivo insulin action is familial characteristic in non-diabetic Pima Indians. Diabetes 36: $1329-1335$

17. Steele R (1959) Influences of glucose loading and of injected insulin on hepatic glucose output. Ann NY Acad Sci 82: 420-430

18. Golay A, Schutz Y, Meyer HU, Thiébaud D et al. (1982) Glucose induced thermogenesis in non-diabetic and diabetic obese subjects. Diabetes 31: 1023-1028

19. Taylor R, Ram P, Zimmet P, Raper R, Ringrose H (1984) Physical activity and prevalence of diabetes in Melanesian and Indian men in Fiji. Diabetologia 27: 578-582

20. King H, Zimmet P, Raper L, Balkau B (1984) Risk factors for diabetes in three Pacific populations. Am J Epidemiol 119: 396409

21. Schoeller DA, Ravussin E, Schutz Y, Acheson KJ, Baertschi P, Jéquier E (1986) Energy expenditure by doubly labeled water: validation in humans and proposed calculation. Am J Physiol 250: R823-R830

22. Efendic S, Wajngot A, Vranic M (1982) Hepatic futile cycle is an important metabolic pathway in lean Type 2 diabetics. Diabetes 31 [Suppl 1]: 282 (Abstract)

23. Felig P, Wahren J, Hendler R (1978) Influence of maturity-onset diabetes on splanchnic glucose balance after oral glucose ingestion. Diabetes 27: 121-126

24. Davidson IWF, Salter JM, Best CH (1960) The effect of glucagon on the metabolic rate of rats. Am J Clin Nutr 8:540-545

25. Halter JB, Porte D Jr (1977) Increased adrenergic activity in diabetes mellitus. Response to therapy and pharmacologic stimulation. Clin Res 25: 160A (Abstract)

26. Payne PR, Waterlow JC (1971) Relative requirements for maintenance, growth and physical activity. Lancet II: $210-211$

27. Kolterman OG, Gray RS, Griffin J, Insel J, Scarlett JA, Olefsky JM (1981) Receptor and postreceptor defect contribute to the insulin resistance in non-insulin-dependent diabetes mellitus. $\mathbf{J}$ Clin Invest 68: 957-969

28. Best JD, Judzewitsch RG, Pfeifer MA, Beard JC, Halter JB, Porte D Jr (1982) The effect of chronic sulfonylurea therapy on hepatic glucose production in non insulin-dependent diabetes. Diabetes 31: 333-338

29. DeFronzo R, Simonson D, Ferrannini E (1982) Hepatic and peripheral insulin resistance: a common feature of Type 2 (non-insulin-dependent) and Type 1 (insulin-dependent) diabetes mellitus. Diabetologia 23: 313-319

30. Campbell P, Mandarino L, Gerich J (1988) Quantification of the relative impairment in actions of insulin on hepatic glucose production and peripheral glucose uptake in noninsulin-dependent diabetes mellitus. Metabolism 37: 15-22

31. Bogardus C, Lillioja S, Howard BV, Reaven G, Mott D (1984) Relationship between insulin secretion, insulin action and fasting plasma glucose concentration in non-diabetic and noninsulin-dependent diabetic subjects. J Clin Invest 74: 1238-1246

32. Reichard GA, Moury NF, Hochella NT, Patterson AL, Weinhouse S (1963) Quantitative estimation of the Cori cycle in humans. J Biol Chem 238: 495-501

33. Waterhouse C, Keilson $J$ (1969) Cori cycle activity in man. J Clin Invest 48: 2358-2366

34. Zawadski JK, Wolfe RR, Mott D, Lillioja S, Howard BV, Bogardus C (1988) Increased rate of Cori cycle in obese subjects with NIDDM and effect of weight reduction. Diabetes 37: 154-159

35. Chochinov RH, Bowen HF, Moorhouse JA (1978) Circulating alanine disposal in diabetes mellitus. Diabetes 27: 420-426

36. DeMeutter RC, Shreeve WW (1963) Conversion of DL-lactate $2{ }^{14} \mathrm{C}$ or pyruvate $2-{ }^{14} \mathrm{C}$ to blood glucose in humans: effect of diabetes, insulin, tolbutamide and glucose load. J Clin Invest 42: 523-533

37. Comstock JP, Ellerhorst JA, Garber AJ (1987) Effect of sulfonylurea therapy on glucose-alanine precursor-product interrelationships in NIDDM. Diabetes 36 [Suppl 1]: 4A (Abstract) 
38. Consoli A, Nurjhan N, Capani F, Gerich J (1989) Predominant role of gluconeogenesis in increased hepatic glucose production in NIDDM. Diabetes 38: 550-557

39. Consoli A, Nurjhan N, Reilly JJ, Bier D, Gerich JE (1990) Mechanism of increased gluconeogenesis in non insulin-dependent diabetes mellitus. J Clin Invest 86: 2038-2045

40. Katz J (1985) Determination of gluconeogenesis in vivo with ${ }^{14} \mathrm{C}$ labeled substrates. Am J Physiol 248: R391-R399

41. Williamson J, Kreisberg RA, Felts PW (1966) Mechanism for the stimulation of gluconeogenesis by fatty acids in perfused rat liver. Proc Natl Acad Sci USA 56: 247-254

42. Bagdade JD, Porte D Jr, Bierman EL (1969) The interaction of diabetes and obesity on the regulation of fat mobilization in man. Diabetes 18: 759-772

43. Unger RH, Aguilar-Parada E, Meuller WA, Eisentraut AM (1970) Studies of pancreatic alpha-cell function in normal and diabetic subjects. J Clin Invest 49: 837-845

44. Baron AD, Schaeffer L, Shragg P, Kolterman OG (1987) Role of hyperglucagonemia in maintenance of increased rates of hepatic glucose output in Type 2 diabetics. Diabetes 36: 274-283

45. Stevenson RW, Steiner KE, Davis MA et al. (1987) Similar dose responsiveness of hepatic glycogenolysis and gluconeogenesis to glucagon in vivo. Diabetes 36: 382-389
46. Christensen NJ (1974) Plasma norepinephrine and epinephrine in untreated diabetics, during fasting and after insulin administration. Diabetes 23: 1-8

47. Christensen NJ (1971) Plasma catecholamines in long-term diabetics with and without neuropathy and in hypophysectomized subjects. J Clin Invest 51: 779-787

48. Robertson RP, Halter JB, Porte D Jr (1976) A role for alphaadrenergic receptors in abnormal insulin secretion in diabetes mellitus. J Clin Invest 57: 791-795

Received: 28 January 1992

and in revised form: 6 A pril 1992

Dr. A.M. Fontvieille

National Institutes of Health

4212 N. 16th St., Room 541

Phoenix, AZ 85016

USA 